\title{
Ángeles Romero Cambrón \\ Los posesivos en la producción herediana (ensayo de panorámica general sobre el aragonés)
}

\begin{abstract}
The purpose of this paper is to study some features of the grammar of possessives in the works of Juan Fernández de Heredia, and, by widening the corpus, in the Aragonese dialect as a whole. An analysis is carried out of the construction el suyo fillo as well as of the use of the possessive placed after the noun, especially with an article (el fillo suyo). A hypothesis is defended that the characteristic solution for the possessive in Aragonese is the construction including the article, whether the possessive is placed before the noun (el suyo fillo) or after it (el fillo suyo). Aragonese would thus coincide with Catalan (el meu fill, el fill $\mathrm{meu}$ ) in this respect.
\end{abstract}

Keywords: Possessive, possessive before the noun, possessive after the noun, Aragonese, Juan Fernández de Heredia, historical linguistics, Romance linguistics

Posesivos, posesivo antepuesto, posesivo pospuesto, aragonés, Juan Fernández de Heredia, Lingüística histórica, Lingüística románica

Prof. Dr. Ángeles Romero Cambrón: Universidad de Castilla-La Mancha, Departamento de Filología Hispánica y Clásica, Avda. Camilo José Cela, s/n, E 13071 Ciudad Real, E-Mail: Angeles.Romero@uclm.es

\section{Introducción}

El objeto del presente trabajo es analizar algunos rasgos de la gramática de los posesivos en las obras promovidas por Juan Fernández de Heredia (1310?-1396). El corpus elegido resulta adecuado como base de un estudio lingüístico por su extensión, pero, sobre todo, porque reúne textos copiados poco después de su redacción (datables en una horquilla temporal de aproximadamente veinte o treinta años). ${ }^{1}$ Todos ellos pertenecen al dialecto aragonés, caracterizado precisa-

1 La transcripción de Nitti/Kasten (1997) y su inclusión en el CORDE facilitan enormemente la consulta del conjunto de obras del sanjuanista. Además, he contado con la versión en soporte 
mente por su falta de homogeneidad interna. Tradicionalmente se han distinguido en él las variedades norteñas de las del sur, como hacen en fecha reciente Enguita (2008, 92-99; 2009) y Enguita/Lagüéns (1989), pero sin duda hay que prestar atención también a la diversidad existente entre las orientales y occidentales, tal como ya sugirió Vives (1927, 31ss.) al clasificar lingüísticamente las obras auspiciadas por el Gran Maestre.

Hasta ahora, todos los esfuerzos de los investigadores se han consagrado a establecer el uso del posesivo lur (< ILLŌRUM) en los distintos títulos heredianos (Vives 1927, 32; Badia Margarit 1963, 329s.; Geijerstam 1980, 498-501; Âlvarez Rodríguez 2009, LXXXI). Lo dicho sobre el particular me parece suficiente y bien enfocado. Me propongo, por tanto, en esta ocasión atender a otro aspecto: el del empleo de la nueva serie de posesivos tónicos tuyo y suyo (con mío y mía en la primera persona de singular). En concreto, someteré a examen dos cuestiones. En primer lugar, me ocuparé de la construcción que puede ejemplificarse en el suyo fillo, es decir, la que sigue el esquema artículo + posesivo tónico + sustantivo. En segundo lugar, intentaré determinar hasta qué punto se emplea el posesivo pospuesto al sustantivo, en especial cuando a este le precede el artículo, como en el fillo suyo. El tratamiento de otros contextos sintácticos donde se produce la posposición del posesivo será sumario, pues requiere de mayor atención de la que ahora puedo prestarle. En la medida de lo posible, intentaré poner en relación los datos obtenidos en el examen del corpus herediano con cuanto se sabe del dialecto antiguo y de su pervivencia en el habla viva, a fin de trazar, siquiera sea provisionalmente, una visión panorámica del aragonés.

\section{La construcción el suyo fillo}

Para el periodo considerado, segunda mitad del siglo XIV, hay ya dos cambios bien asentados en los posesivos, al menos en Castilla. El primero de ellos sería la implantación muy consolidada de la estructura sin artículo: mio fijo gana terreno a el mio fijo. ${ }^{2}$ El segundo es la extensión de las formas originariamente femeninas

electrónico de todas las ediciones heredianas elaboradas por el equipo de investigación dirigido por Adelino Álvarez (CIGYT, PS95-0106 y PB98-0311), cuya ficha bibliográfica queda consignada en el apartado de fuentes. Debo agradecer de manera especial a Marcos Herraiz y al prof. Álvarez que hayan puesto generosamente a mi disposición su edición, inédita aún, del Eutropio. He podido trabajar también con la edición del Isidoro «Menor» de Francisco Javier García de León, igualmente inédita.

2 La construcción artículo + posesivo + sustantivo en el conjunto de la Romania ha sido muy atendida por la bibliografía. De especial interés resultan los datos reunidos sobre este punto por 
al masculino en posición prenominal. En la primera persona de singular, durante mucho tiempo se mantuvo la oposición (la) mi fija y (el) mio fijo, aunque ya a finales de la centuria se había impuesto la forma única: (la) mi fija y (el) mi fijo. En la segunda y tercera persona de singular también se difunde la forma invariable tu y su. Las formas tónicas de la primera persona de singular son las plenas sin apócope: mía, mío. Un tercer cambio lo representa, no ya el surgimiento, sino la extensión a determinados contextos sintácticos de las nuevas formas tónicas de segunda y tercera persona, tuyo y suyo. En Castilla habían consolidado su empleo en tres contextos sintácticos (Romero Cambrón 2009): como atributo (es suyo), como término de preposición (por suyo) y con el artículo en construcciones anafóricas (el suyo). En las personas del plural, por supuesto, no podemos percibir ningún cambio, pues nuestro/- $a$, vuestro/- $a$ y lur (en caso de que este existiera en la variedad dialectal correspondiente) son formas únicas para cualquier contexto sintáctico: (el) vuestro fillo, es vuestro, por vuestro, el vuestro. Nuestra construcción, pues, solo se manifiesta con las formas tuyo y suyo. En buena parte de las obras heredianas, aunque no en todas, hallamos documentado el esquema el suyo fillo.

\subsection{Documentación}

Este empleo de tuyo y suyo registrado en los textos heredianos se halla muy esporádicamente en el siglo XIII:

(1) A los tuyos clamantes tú los deña oír (Santo Domingo, 764c, CORDE, apud Company Company 2009b).

(2) Las suyas ondas blancas \& cárdenas (Alfonso X, Estoria de España, f. 351v, CORDE, apud Company Company 2009b).

También registro dos casos en los Documentos lingüísticos del Alto Aragón de Navarro Tomás (DLAA a partir de ahora), desfrutados al completo:

(3) [En el] nomne de Jhesu Christ edela suya gracia (DLAA, no 28, 1274, Huesca).

(4) Non uienga al monasterio de Sant Johan de la Penna ni a las suyas villas (DLAA, no 75, 1299, Jaca).

Lausberg (1965), Rohlfs (1966-1969), Pino Serrano (1996) y García Martín (2010). Sería mi intención consagrar a este tema un estudio aparte. 
Este otro ejemplo es del XIV:

(5) Todos los suyos caualleros (Crónica de 1344, CORDE, apud Company Company 2009b).

En el corpus herediano hay obras en las que el mencionado empleo de tuyo y suyo no se documenta: es el caso de la Flor de historias de Orient, del Marco Polo, del Secreto de los secretos, del Tucídides y del Libros de los fechos y de las conquistas de la Morea; en este grupo, el ejemplo más revelador es el del Orosio, por ser, con mucho, la obra más extensa (265folios), seguido del caso de la Historia troyana (182folios). En otras se da de forma testimonial: así sucede en el llamado Cronicon mundi (4/110f.: 3,33\%)3 , en el Emperadores (6/180f.: 3,33\%) y en el Plutarco (13/ 708f.: 1,83\%). En cambio, en dos obras, el Rams de flores y el Eutropio, este uso de tuyo y suyo es corrientísimo, con un porcentaje respectivamente del 53/138f. $(38,4 \%)$ y $29 / 120 f .(24,16 \%)$. Aduciremos algunos testimonios:

(6) Los tuyos prinçeps malos son leales a los ladrones (Rams, f. 137r).

(7) La suya graçia (Rams, f. 147d).

(8) San Matheo en el suyo euangelio (Rams, f. 156a).

(9) Car no pudo sofrir la lamp ni la resplandor de los tuyos ojos (Eutr., f. 48d).

Los datos de las crónicas deben ser considerados con precaución debido a la pluralidad de las fuentes empleadas en ellas: la presencia es residual en la Grant crónica de Espanya, primera partida, (GCE 1 , 8/625f.: 1,28\%), en la GCE $\mathrm{G}_{3}$ (3/293f.: $1,02 \%$ ) - versión esta última de un original castellano - y también en la Grant crónica de conquiridores, primera partida ( $\mathrm{CC}_{1}$ 12/237f.: 5,0\%); no así en la segunda partida $\left(\mathrm{CC}_{2}, 55 / 437 \mathrm{f} .:\right.$ 12,50\%).

\subsection{Análisis}

En las obras heredianas que conocen esta construcción, un sustantivo con posesivo podía adoptar cuatro esquemas: su fillo, el su fillo, el suyo fillo y el fillo suyo. En castellano, la forma con artículo, opción más arcaizante, pervivió durante un largo periodo como variante «marcada», usada por ejemplo cuando existía un matiz afectivo especial o en el tratamiento deferente. ${ }^{4}$ Este valor estilístico se registra perfectamente en el Orosio para la construcción con artículo ordinaria:

3 Indico a la izquierda de la barra el número de ocurrencias y a la derecha el número de folios. Paso a tantos por ciento para facilitar la comparación.

4 Es esta cuestión muy estudiada: cf. el trabajo clásico de Lapesa (1971) y el más de reciente de Company Company (2009a) y la bibliografía en ellos recogida. 
(10) Padre sant Agostín, en fazer aquesti libro he yo obedecido a los tus mandamientos [...] Yo so contento del testimonio de la sola obediencia, si la afeité e la firmé en la mi voluntat e en el mi esfuerço en tanto cuanto yo pudiesse obedecer a los tus mandamientos (Oro., f. 9c).

Interesa subrayar, no obstante, que el empleo del artículo no entraña ningún tipo de relevancia estilística, como se desprende de la utilización de las dos fórmulas para el mismo contexto:

(11) a. En el cuarto anyo de su imperio (Oro., f. 215a).

b. En el anyo del su imperio XVII (Oro., f. 215a).

Del mismo modo, el artículo con tuyo y suyo aparece como forma estilísticamente «marcada», como vemos en (12), pero no necesariamente, tal como se aprecia en (13):

(12) La tuya casa [del Señor] (Rams, f. 149a).

(13) El no auia millor ansia en quiento estamiento seria la comunidat apres la suya muert que en la su vida (Rams, f. 127d).

Tal como acreditan los tres ejemplos aducidos al principio, uno de Berceo y los otros dos documentados por Navarro Tomás en los Documentos lingüísticos del Alto Aragón (DLAA), la construcción el suyo fillo estuvo adscrita a un ámbito geográfico concreto, el constituido por La Rioja y Aragón, donde debió estar bien arraigada en el periodo medieval. Aún hoy subsiste en el dialecto: Badia Margarit (1950, 115s.) da como formas genuinas en el valle de Bielsa pal mío libro, la tuya casa; Haensch $(1960,137 \mathrm{~s}$.) describe el mismo paradigma de posesivos para la Alta Ribagorza; Alvar/Pottier $(1983,101)$ recogen o suyo mocé ['hijo'].

Si efectivamente ocurrió así, con respecto a la producción herediana cabe preguntarse: ¿por qué la presencia en ella es, en muchas obras, nula o marginal? No hay que dejar de contar con la existencia de diferencias internas dentro del propio aragonés, tal como ya se ha señalado, y con la adhesión a una u otra de las soluciones concurrentes de los diversos actores que trabajaron en las traducciones y crónicas del Gran Maestre. ${ }^{5}$ Con todo, parece razonable suponer que el suyo fillo se consideraba una variante de poco prestigio para el uso literario, a pesar de que estuviera bien asentada en el coloquio. Así podría explicarse que el Orosio, una obra de redacción tan cuidada, la desconozca. La fuente empleada en cada caso debió igualmente pesar. En la tercera partida de la GCE, versión de la

5 Consciente de que los textos, tal como han llegado a nosotros, son el resultado final de la actuación de diversas manos, Geijerstam (1996, 161-169) propuso emplear en su estudio lingüístico que denominó «método arqueológico» para deslindar lo que se debe al redactor, al corrector, al copista. 
castellana Crónica de veinte reyes, solo asoma tres veces. En cambio, la influencia catalana ayudó seguramente al afloramiento de la forma patrimonial y descuidada: es el caso del Eutropio, donde hallamos catalanismos crudos abundantísimos hasta en la propia morfología verbal (Herraiz Pareja/Álvarez Rodríguez, inédito); y también puede ser el del Rams, obra para la que Cacho Blecua (1999) supone un antecedente catalán.

\subsection{Origen de la construcción}

A pesar de ser una construcción relativamente poco documentada, el suyo fillo plantea cuestiones de interés. Su surgimiento solo pudo tener lugar si se cumplían necesariamente una serie de condiciones:

a) Que la construcción genuina en aragonés fuera la del posesivo con artículo. De hecho, la construcción no se documenta nunca sin que este le preceda:

(14) * Suyo fillo.

A la existencia de el suyo fillo debe sumarse la del tipo el fillo suyo, con posposición del posesivo (cf. 3.2), además de los casos del tipo el su fillo. En esta misma línea apunta el hecho de que la presencia del artículo ante el posesivo pueda considerarse la forma «no marcada» tal como se desprende de los ejemplos de (13) arriba.

b) La difusión plena de las formas analógicas tuyo y suyo, originadas, según creo (Romero Cambrón 2009), justamente en el ámbito riojano y aragonés. Para finales del siglo XII y principios del XIII, ambas están perfectamente asentadas en los tres contextos señalados antes (atributo, término de preposición y artículo con valor anafórico). En cualquier caso, puesto que se emplean las mencionadas formas del posesivo, este tras el artículo es siempre tónico.

c) La presencia, siquiera fuera marginal, de las formas plenas femeninas túa y súa. No estamos aquí en el terreno de las suposiciones: estas formas aparecen en efecto en el corpus herediano. En el Rams se cuentan cuatro ocurrencias; en el Eutropio tres; dos en Emperadores; y una en la $\mathrm{GCE}_{1}$, en la $\mathrm{CC}_{2}$ y en las Historias de Orient. Las correspondientes masculinos analógicos túo, súo asoman una vez en la $\mathrm{GCE}_{1}$ y otra en el Secreto. No debe sorprender que estas formas arcaicas no se documenten en el Orosio, redactado, como ya he señalado antes, con especial esmero. 
d) La presencia, aunque sea residual, de las formas no apocopadas del posesivo de primera persona singular, no solo masculino, sino también femenino, en la construcción con artículo (la mía filla, el mío fillo). En el mismo Rams, la mía más sustantivo aparece un total de quince veces:

(15) La mia persona (Rams, f. 117v); la mia lengua (Rams, 120v); la mia sanya (Rams, f. 131r) ...

En el Eutropio hay cinco casos de la mía más sustantivo. En el Plutarco tenemos las mías adversidades (f. 205 v), la mía estatua (f. 126r), y en $\mathrm{CC}_{2}$ tenemos un la mía muert (141v); hasta doce veces se registra el femenino no apocopado en la GCE . Asimismo, documentamos el mío más sustantivo: tres veces en $\mathrm{GCE}_{3}$, una vez en el Eutropio.

e) Las personas del plural, en las que no hay distinción formal para los posesivos en contextos tónicos y átonos, reforzarían la extensión de una solución única. Ejemplos como los siguientes dan idea de la implantación de tuyo y suyo en posición prenominal:

(16) Dos suyos amigos (Plut., f. 146v).

(17) Uno suyo sieruo (Rams, f. 242r).

\section{El posesivo pospuesto al sustantivo}

Hasta ahora hemos venido señalando que el uso de los posesivos tónicos, en particular las nuevas formas tuyo y suyo, se había impuesto en tres contextos sintácticos ya indicados: la función de atributo, como término de una preposición y con el artículo con valor anafórico. Si se realiza una comparación con la lengua actual, enseguida se echa en falta un contexto más, exclusivo de las formas tónicas: estas son también posibles pospuestas al sustantivo (el libro suyo, por culpa mía, dos libros suyos, estos libros suyos). Cornu (1884, 310) y Menéndez Pidal (1908-1911, 257) indicaban que en esta posición el posesivo era raro en el siglo XIII y solo se registra más abundantemente en el XIV. ${ }^{6}$ Company Company (2009b, 772) confirma y precisa esta observación: en posposición al sustantivo el posesivo se atestigua por primera vez en el corpus por ella reunido a inicios del siglo XIV y

6 Doy el único caso que he hallado del antiguo posesivo so pospuesto, en los Documentos Lingüísticos de Menéndez Pidal: «Fago me familiar so» (no 49, Vileña, part. de Briviesca, 1225). 
su empleo se vuelve algo más frecuente a mediados y a finales de este siglo. Para el XV, según Eberenz (2000, 293-298), la posposición aparece en muchos textos, aunque no se aprecia un aumento de su uso a lo largo de la centuria.

\subsection{Documentación en el dominio oriental durante el siglo XIII}

Sin embargo, esta escasa implantación del posesivo tras el sustantivo en el siglo XIII tiene que ser matizada. Es cierta por lo que se refiere a textos castellanos, pero parece no corresponder a la realidad en textos escritos en el dominio situado al oriente de Castilla. No considero algunos ejemplos aislados de posesivos pospuestos pertenecientes a esta centuria que recoge el CORDE extraídos de diversos fueros por habérsenos transmitidos todos en copias tardias. ${ }^{7}$ Ahora bien, desfrutando los DLAA al completo, pueden hallarse al menos un centenar de posesivos pospuestos en el siglo XIII (contando mía, mío, tuyo, suyo, nuastro, nuestro, vuastro, vuestro, lur). Doy a continuación una muestra que recoge varios contextos sintácticos:

(18) A profieyto vuestro [...] uos \& fillos \& fillas uestros (DLAA, $\mathrm{n}$ 0 3, 1269).

(19) Yo Maria Palatz, muller suya; vna vigna nuastra [...] uos \& fillos \& fillas uuastras a toda generacion \& posteridat uuastra (DLAA, no 9, 1266).

(20) Con atorgamiento \& volontat de Johan de Sora \& de dona Johana, fillos mios, do \& lexo auos dona Acnes \& a uos dona Guillema, amadas fillas mias, todas \& quiscunas las heredades, las quales son \& seer deuen de la capellania nuastra de la glesia de San Pere Vieillo dUasca [...] segon que se conteneig en el testament nuestro, que sia dona \& poderosa de tener la dita capellania, ellos \& fillos \& fillas \& generacion \& posteridat suya (DLAA, $\mathrm{n}-12,1268)$.

(21) Yo Pedro dOla \& Dominga muller mja, qui habitamos en Molins [...] vendemos auos Pedro Santa Cruç \& adana Maria muller uuestra, ueçinos dUasca, tres canpos que emos enlauilla de Molins, \& en terminos suyos [...] sienes ningun retenimjento nuestro, consos entradas \& lures exidas \& con todos lures dreytos \& lures pertinencias \& segunt que nos \& antecessores nuestros nunca millores tenjentes enfuemos (DLAA, $n$ no 20, 1271).

(22) Con esta present carta, apres dias tuyos, dotra persona que fillyo tuyo sia, vna tienda nuestra, apres dias vuestros (DLAA, $\mathrm{n}-25,1273$ ).

(23) Nieta mia [...] sobre la fuesa mia (DLAA, $\mathrm{n}$ - 71, 1295).

(24) Por al seruicio suyo (DLAA, no 74, 1299, part. de Sos).

(25) Con carta suya bullada (DLAA, $\mathrm{n} 024,1272$ ).

(26) Tres campos nuestros (DLAA, $\mathrm{n}-23,1272$ ).

(27) Vn campo nuestro que auemos (DLAA, no 63, 1292).

7 Es el caso del Fuero de Viguera y Val de Funes, el de Soria, el Fuero General de Navarra o incluso el de Zorita de los Canes. 
A estos datos habría que sumar los que se encuentran en la obra de Berceo, un total de veintitrés, de acuerdo con los datos recogidos en el CORDE. Todos se inscriben en alguno de los tres esquemas apuntados (con artículo antepuesto al sustantivo, como término de una preposición o como atributo):

(28) Las oraciones tuyas son de Dios exaudidas (Santo Domingo, 718a, CORDE).

(29) a. Por cancellario mío yo a éssi tenía (Milagros, 109d, CORDE).

b. Mas en memoria suya que fuesse renovada (Sacrificio, 168d, CORDE).

(30) Fue salvador mío (Milagros, 766d, CORDE).

Si damos por buenos estos datos documentales referidos al siglo XIII, el uso del posesivo pospuesto en la producción herediana debe entenderse como continuación de un hábito lingüístico ya asentado en aragonés y en riojano.

\subsection{La construcción el fillo suyo}

De todos los contextos donde es posible el posesivo pospuesto, destaca aquel donde el artículo precede al sustantivo, es decir, el tipo el fillo suyo. Sorprende la abundancia con que se emplea, muy elevada a lo que se colige de la lectura de las obras del hospitalario (aun en las que no conocen la construcción el suyo fillo), y mayor, según parece sin duda, de la que tiene en español actual. Sorprende que, del mismo modo, a diferencia de lo que ocurre en este, su utilización no se vea inducida por la aparición de ninguna circunstancia expresiva relevante:

(31) a. La cabeça de Graco cortada fue aducha al cónsul e el cuerpo suyo fue levado a Cornilia, su madre (Oro., f. 150a).

b. Él fuesse bienaventurado entro a la fin de la vida suya (Plut., f. 34v).

(32) E como Almezorre vidies fuir los suyos assí viturperosament, indignado, saltó de la cadira reyal en tierra porque Almezorre mostrava aquest senyal de calumpnya a los sus cavalleros demientre mal batallavan que se levantava el capel de la cabeça, el cual era de oro e sedié en tierra con calumpnya; e los cavalleros suyos vidientes lo su captanimiento, amonestauense los unos a los otros e encercaron los nuestros con sanya (Cronicon, f. 86a).

(33) E las mujeres lures qui eran en huest sallieron de las tiendas con segures en las manos e con otras armas (Plut., 191r).

Esta posposición se da también con lur, como se ve en el ejemplo anterior de (33) y en este otro:

(34) Por la gentileza e bondat lur (Plut., f. 70r). 
Completemos nuestros datos sobre el dominio aragonés. Enguita $(2009,127)$ da asimismo como característica la construcción con artículo y posesivo pospuesto para la documentación medieval zaragozana.

Si tomamos en consideración los datos obtenidos del examen de la obra de Berceo, este pudo bien ser uno de los primeros contextos donde el posesivo apareciera pospuesto. En el primer ejemplo de los dos siguientes, alterna el posesivo pospuesto con artículo con las otras dos posibilidades, el posesivo antepuesto sin artículo, y con artículo y antepuesto:

(35) E cómo muchos reyes partién de lurs regnos por servirlo. E de las condiciones suyas buenas, e de la disposición e qualidat de su cuerpo, e de las sus malas condiciones (Eutr., f. 11a).

(36) E aquésta no es pont cosa irrazonable si alguno espiende de lo suyo proprio, no solament por su provecho, mas encara por el provecho de la ciudat suya (Tuc., f. 50c).

De nuevo parece - la información que tenemos sobre este particular es escasa y a veces poco fiable - que la construcción documentada en la lengua antigua halla continuidad en el habla moderna. A juzgar por los datos del ALEANR, que recoge encuestas realizadas entre 1963 y 1968 (mapa 1.743), la construcción con artículo y posesivo pospuesto era, en aquella época, la forma habitual no enfática de colocación del posesivo en parte del dominio aragonés. ${ }^{8}$ Algunos datos más podemos espigar, entre el abrumador predominio de las soluciones coincidentes con la lengua estándar, en el COSER, para fecha más reciente: ${ }^{9}$

(37) La mujer mía tenía, cuando se murió, sesenta (San Mateo de Gállego, Zaragoza, COSER-4719, varón de 84 años).

(38) [...] Diez hombres a vendemar andando [...] el albergue nuestro era el pajar.

(39) Es que estábamos... En como en el pueblo nuevo estaba sin terminar, estábamos muchos en el pueblo viejo. Yo viví en el pueblo viejo mientras pude en la casa mía (Almonacid de la Cuba, Zaragoza, COSER-4706, varón de 82 años).

(40) La aguja mía [...] (Fuentes Claras, Teruel, COSER-4117, mujer de 62 años). ${ }^{10}$

Añadamos una precisión más, referida al corpus herediano. Si es posible la posposición del posesivo con el artículo, no extraña que lo sea también con el demostrativo. Encuentro, sin detenerme a buscar de manera específica, estas dos ocurrencias en la $\mathrm{GCE}_{1}$ :

8 Agradezco a Vicente Lagüéns los reveladores datos que me ha proporcionado relativos a la lengua viva, coincidentes con los del atlas citado.

9 Expreso aquí mi reconocimiento a Inés Fernández-Ordoñez, que me ha hecho llegar archivos del corpus aún no disponibles en Internet.

10 Aun encuentro otro caso en La Rioja (Huércanos, COSER-2506). 
(41) Aquell fillo suyo (f. 59r).

(42) Aquesti ermano suyo (f. 81r),

y una en el Cronicon:

(43) Aquel mismo fillo suyo (f. 9b).

\subsection{Otros contextos donde aparece el posesivo pospuesto}

Hemos examinado el esquema artículo + sustantivo + posesivo. Volvamos a los ejemplos citados arriba tomados de los DLAA y de Berceo. Mención merece, aunque solo sea de pasada, el uso, suficientemente representado en la documentación, del posesivo pospuesto, sin artículo, pero con carácter definido: «uos \& fillos \& fillas uestros», en (18) y (19); «apres dias tuyos», en (22). Esta última fórmula la encuentro recogida también en un diploma dado en Calatayud en el año 1411 incluido en el CODEA:

(44) La qual aya el usufructo de aquélla por todo tiempo de su vida e aprés días suyos dexo la dita pieça al prior e capítol de la iglesia de Santa María de la Peña (no 908, Calatayud, Zaragoza, CODEA).

Consideremos en este último apartado otros contextos sintácticos donde también se pospone el posesivo. Lo destacable, de nuevo, es la frecuencia con que esta se registra en el conjunto de tales usos. Los dos primeros se caracterizan por ser en ellos habitual la omisión del artículo:

19) En sintagmas nominales que funcionan como atributos. En este contexto, el sintagma nominal tiene una interpretación habitualmente atributiva, no referencial. Para este valor, no encontramos la posposición en (44), pero sí en (45):

(45) Los parientes míos eran vuestros amigos (Tuc., f. 63a).

(46) Car su ermana Costancia era muger suya (Eutr. f. 63d).

2oㅡ En sintagmas nominales que funcionan como término de una preposición:

(47) Reduxo en su amor e en servitut suya toda la gent de Paquiano (Plut., f. 293c).

(48) Por memoria suya e por su honor su madre Octavia offreció la biblioteca (Plut., f. $86 \mathrm{v})$. 
3ํ) En la aposición especificativa:

Para la aposición especificativa, la prosa herediana conoce dos órdenes: se antepone bien el nombre común (su filo Alexandre), bien el nombre propio (Alexandre su fillo). Las dos alternativas son muy corrientes en una obra como el Orosio. En el segundo caso, cuando el nombre común se pospone y lleva un posesivo, este último, además de ir antepuesto, también puede ir pospuesto (véanse además los ejemplos ya recordados de los DLAA de (19) y (21) arriba):

(49) En la cual encara lo venció e lo priso. El cual preso, uno clamado Diodotus con su fillo Alexandre usurpó el regno suyo e tomó el nombre real. El cual después mató al dicho Alexandre, fillo suyo (Oro., f. 140cd).

La posposición del posesivo es más frecuente que su anteposición en obras como el Eutropio. Obsérvese que, dado que padre o madre no hay nada más que uno y necesariamente han debido existir, el sustantivo es determinado en los siguientes ejemplos:

(50) Herenio, padre suyo (Eut., f. 23b).

(51) Antípater mató con su mano a Thesalonice, madre suya e muller de Casandro (Oro., f. 97b).

(52) E la infanta Sancha fizo grant planto sobre el duc García e enterró aquel honorablement cerca el rey Aldefonso, padre suyo (Cronicon, f. 89b).

La misma fórmula la hallo bien atestiguada en el CODEA, en documentos oscenses del XIII y del XIV:

(53) Manifiesta cosa sía a todos cómo yo Domingo, fillio que fue de don Joán Dorús, e yo Sancha, muller suya (no 1413, Belsúe, Huesca, 1290),

y en documentos zaragozanos:

(54) Gil e Teresa, fijos de los ditos don Gil de Molina e de doña Sicilia, muger suya (№ 0740, Calatayud, Zaragoza, 1346).

40) Con vocativos:

(55) O, fillo mío (Plut., f. 181r).

(56) Senyores ayudadores nuestros (Plut., f. 87r).

5ㅇ) El posesivo con cuantificadores:

No resulta fácil historiar una estructura tan poco frecuente. No obstante, parece claro que, cuando el posesivo concurre con un cuantificador, en los 
primeros textos peninsulares este precedía a aquel (cf. Camus Bergareche 2009, 893ss.): ${ }^{11}$ un su fillo, dos sus fillos, algunos sus fillos, muchos sus fillos, un otro su fillo, el otro su fillo, otro su fillo. Semejante esquema posicional también se emplea en toda la obra herediana; de hecho, en los textos castellanos pervive junto a la forma nueva con posesivo pospuesto (un hijo suyo ...) incluso en el siglo XVI, tal como estudia Keniston (1937, 242-248):

(57) Una su fija (Oro., f. 36a).

(58) Dos sus fillos adolecentes (Oro., f. 45a).

(59) Algunos sus gentiles hombres (Plut., f. 7v).

(60) E diziendo assí de una part, de otra aplegava tanta huest quanta los romanos no han jamás aplegado contra algún lur enemigo (Plut., f. 185v).

(61) Quando Clauso consideró bien esta cosa, pareciole bueno segunt la necessidat e comovió a muchos otros sus amigos (Plut. f. 84v).

(62) Aquesta Cornilia era filla del Mayor Cipión Africano e havíase ido al castillo de Mecina por la muert del otro su fillo el primero (Oro., 150a).

(63) Esti Olthaco, quanto a fortaleza e a ardideza de combater, era maravelloso, e muit sufficient de dar consejo en caso de necessidat, e bien favlant, e consolava a todo hombre con sus paravlas, mas él havía invidia con otro su semblant (Plut., f. 81r).

En el Eutropio encontramos el mismo esquema cuantificador más suyo, como se aprecia en (64). Repetimos los ejemplos de (16) (17) arriba, de la misma naturaleza:

(64) Aquesta començó a Sílere Fluvio, ab Brictcia, la qual así es clamada por nombre de alguna suya regina (Eut., f. 95a).

(65) Dos suyos amigos (Plut., f. 146v).

(66) Uno suyo sieruo (Rams, f. 242r).

Falta realizar estudios contrastivos con textos contemporáneos y de otra procedencia geográfica. Ahora bien, por lo que respecta a la literatura herediana, son bastante numerosos los casos en que el posesivo va pospuesto: un fillo suyo, dos fillos suyos, muchos fillos suyos, un otro fillo suyo, algún fillo suyo. Sirvan de ilustración estos ejemplos:

(67) E dio aquestas letras a Papías, que tantost las enviás con un servidor suyo a todos los de su liga. (Emperadores, f. 16d).

(68) Fueron presas dos mulleres suyas e dos fillas (Oro. 183b).

(69) Sirven e onran a muchos ministros suyos (Oro., f. 174a).

11 Con el artículo indeterminado, estructura, esta sí, muy frecuente, aún persiste hoy el posesivo antepuesto en algunos ámbitos dialectales (Company Company 2005 y 2009b; Pato 2002). 
(70) E Mitridates vencido fuyó con la muller e con dos companyones. E, muertos dos fillos suyos, Fárnaces, otro fillo suyo, espaordido por exemplo de los ermanos, reconcilió la huest contra sí enviada e levola contra su padre e lo assitió (Eutr., f. 9b).

Mis indagaciones no han sido completas, pero baste, como botón de muestra, este pequeño cuadro, como digo, en absoluto exhaustivo. Ordeno las obras de acuerdo con su extensión. El número de la izquierda corresponde a la estructura con el posesivo pospuesto y el de la derecha a la que lleva el posesivo antepuesto:

Tab. 1: Cuantificadores con posesivos pospuestos

\begin{tabular}{|c|c|c|c|c|c|}
\hline & Plutarco & Orosio & Emperadores & Eutropio & Tucídides \\
\hline $\begin{array}{l}\text { Esquemas } \\
\text { un fillo suyo/un su fillo }\end{array}$ & $\begin{array}{l}3 / 82 \\
\text { registros }\end{array}$ & $\begin{array}{l}0 / 7 \\
\text { registros }\end{array}$ & $\begin{array}{l}2 / 8 \\
\text { registros }\end{array}$ & $\begin{array}{l}1 / 1 \\
\text { registros }\end{array}$ & $\begin{array}{l}0 / 0 \\
\text { registros }\end{array}$ \\
\hline $\begin{array}{l}\text { Esquemas } \\
\text { dos fillos suyos/ } \\
\text { dos sus fillos }\end{array}$ & $\begin{array}{l}3 / 4 \\
\text { registros }\end{array}$ & $\begin{array}{l}3 / 6 \\
\text { registros }\end{array}$ & $\begin{array}{l}0 / 2 \\
\text { registros }\end{array}$ & $\begin{array}{l}6 / 0 \\
\text { registros }\end{array}$ & $\begin{array}{l}0 / 0 \\
\text { registros }\end{array}$ \\
\hline $\begin{array}{l}\text { Esquemas } \\
\text { muchos fillos suyos/ } \\
\text { Muchos sus fillos }\end{array}$ & $\begin{array}{l}2 / 3 \\
\text { registros }\end{array}$ & $\begin{array}{l}4 / 0 \\
\text { registros }\end{array}$ & $\begin{array}{l}0 / 0 \\
\text { registros }\end{array}$ & $\begin{array}{l}1 / 0 \\
\text { registros }\end{array}$ & $\begin{array}{l}0 / 0 \\
\text { registros }\end{array}$ \\
\hline $\begin{array}{l}\text { Esquemas } \\
\text { (un/el/sin especificador) } \\
\text { otro fijo suyo/(un/el) } \\
\text { su otro fillo }\end{array}$ & $\begin{array}{l}0 / 8 \\
\text { registros }\end{array}$ & $\begin{array}{l}1 / 2 \\
\text { registros }\end{array}$ & $\begin{array}{l}0 / 6 \\
\text { registros }\end{array}$ & $\begin{array}{l}3 / 0 \\
\text { registros }\end{array}$ & $\begin{array}{l}0 / 2 \\
\text { registros }\end{array}$ \\
\hline $\begin{array}{l}\text { Esquemas } \\
\text { algún fillo suyo/ } \\
\text { algún su fillo }\end{array}$ & $\begin{array}{l}1 / 16 \\
\text { registros }\end{array}$ & $\begin{array}{l}0 / 0 \\
\text { registros }\end{array}$ & $\begin{array}{l}0 / 0 \\
\text { registros }\end{array}$ & $\begin{array}{l}1 / 1^{12} \\
\text { registros }\end{array}$ & $\begin{array}{l}0 / 0 \\
\text { registros }\end{array}$ \\
\hline
\end{tabular}

Si el nuevo esquema avanza, no sorprende que encontremos ya un sintagma nominal como el siguiente, por entero de acuerdo con las reglas gramaticales de la lengua moderna:

(71) Los dos duques suyos (Cronicon, f. 79c).

12 Contamos aquí el ejemplo (64) del texto: alguna suya regina. 


\section{Conclusiones}

A modo de conclusión, podríamos decir, en primer lugar, que la producción herediana, a pesar de las diferencias existentes entre unas obras y otras, manifiesta la continuidad entre los usos del antiguo dialecto (los DLAA, incluso Berceo) y los documentados por la dialectología en el siglo XX. La solución genuina aragonesa impone la presencia del artículo con el posesivo adnominal. La aparición o no de aquel es el verdadero rasgo diferencial, más que la anteposición o posposición de este, si es acertada la sugerencia de Lausberg (1965, 226). Al admitir la doble posición con el artículo, el aragonés coincidiría con el catalán (el meu fill, el fill $m e u$ ), con la diferencia de que en esta última lengua la posposición representa la variante más enfática (Lausberg 1965, ib.; Brucart 2002, 1502). Si hemos de dar por bueno cuanto acabamos de apuntar, la evolución del aragonés en este punto contrasta claramente con la seguida por el castellano. Este se caracterizó por la temprana pérdida del artículo ante posesivo adnominal, diferenciándose así de manera significativa no solo del aragonés a oriente, sino del leonés a occidente (Menéndez Pidal 1906). Asimismo, me gustaría señalar que las observaciones sobre el posesivo contenidas en este estudio son compatibles con la hipótesis defendida en Romero Cambrón (2009): las formas tuyo y suyo se originaron en la zona riojana o aragonesa. En términos generales, creo que el estudio diacrónico de los posesivos, como el de tantos otros aspectos de nuestra gramática, ha de tener presentes las variantes dialectales existentes en la Península durante la Edad Media.

\section{Bibliografía}

\subsection{Fuentes}

ALEANR = Alvar, Manuel, Atlas lingüístico y etnográfico de Aragón, Navarra y Rioja, en colaboración con Antonio Llorente, Tomás Buesa y Elena Alvar, Zaragoza, La Muralla, 1979-1983.

CODEA = Sánchez-Prieto Borja, Pedro (dir.), Corpus de Documentos Españoles anteriores a 1700 (CODEA), <http://www.textoshispanicos.es> [Consulta:05/02/2013].

CORDE = Real Academia Española (ed.), Corpus Diacrónico del Español (CORDE), <http://corpus.rae.es/cordenet.html> [Consulta: 05/02/2013].

COSER = Fernández-Ordóñez, Inés (dir.), Corpus Oral y Sonoro del Español Rural (COSER), <http://www.uam.es/coser>, 2005ss.[Consulta: 05/02/2013].

DLAA = Navarro Tomás, Tomás, Documentos lingüísticos del Alto Aragón, Syracuse-New York, Syracuse University Press, 1957.

Emperadores = Zonaras, Libro de los emperadores, edición y estudio de Adelino Álvarez Rodríguez; investigación de fuentes bizantinas de Francisco Martín García, Zaragoza, PUZ, 2006. 
Eut. = Eutropio y Paulo Diácono, Compendio de historia romana y longobarda. Versión aragonesa patrocinada por Juan Fernández de Heredia, edición de Marcos J. Herraiz Pareja y Adelino Álvarez Rodríguez, estudio y glosario de Marcos J. Herraiz Pareja, inédito.

García de León Sánchez, Francisco Javier, Estudio y edición del San Isidoro de Sevilla Herediano: el Libro de Sant Isidoro «Menor», trabajo fin de máster, Ciudad Real, Universidad de Castilla-La Mancha, 2010.

Menéndez Pidal, Ramón, Documentos lingüísticos de España, vol. 1: Reino de Castilla, Madrid, CSIC, 1966.

Nitti, John J./Kasten, Lloyd A., The electronic texts and concordances of Medieval NavarroAragonese manuscripts (CD-ROMs), Madison, Hispanic Seminary of Medieval Studies, 1997.

Oro. $=$ Orosio, Paulo, Historias contra los paganos, versión aragonesa patrocinada por Juan Fernández de Heredia. Edición, estudio y vocabulario de Ángeles Romero Cambrón, en colaboración con Ignacio G. García Pinilla, Zaragoza, PUZ, 2008.

Plut. = Plutarco, Vidas semblantes. Versión aragonesa de las «Vidas paralelas», patrocinada por Juan Fernández de Heredia, edición de Adelino Álvarez Rodríguez, 2 vol., Zaragoza, PUZ, 2009.

Rams = Guardiola Alcover, Conrado (ed.), Rams de Flores o Libro de actoridades. Obra compilada bajo la protección de Juan Fernández de Heredia, Maestre de la Orden de San Juan de Jerusalén (edición del ms. de la Real Biblioteca de El Escorial Z- I- 2), Zaragoza, Institución «Fernando el Católico», 1998.

Tuc. = Tucídides, Discursos de la guerra del Peloponeso (Versión aragonesa de la «Historia de la guerra del Peloponeso», patrocinada por Juan Fernández de Heredia), edición crítica y estudio de Adelino Álvarez Rodríguez, Zaragoza, PUZ, 2007.

\subsection{Referencias bibliograficas}

Alvar, Manuel/Pottier, Bernard, Morfología histórica del español, Madrid, Gredos, 1983.

Álvarez Rodríguez, Adelino, cf. Plut. (en 5.1 Fuentes).

Badia Margarit, Antoni, El habla del valle de Bielsa (Pirineo aragonés), Barcelona, CSIC, 1950.

Badia Margarit, Antoni, Tres notas de sintaxis medieval aragonesa, in: Plangg, Guntram A./ Tiefenthaler, Eberhard, Weltoffene Romanistik. Festschrift Alwin Kuhn zum 60. Geburtstag, Innsbruck, Institut für Sprachwissenschaft, 1963, 325-332.

Brucart, Josep Maria, Els determinants, in: Solà, Joan, et al. (edd.), Gramàtica del català contemporani, vol. 2: Sintaxi, Barcelona, Empúries, 2002, 1435-1516.

Cacho Blecua, Juan Manuel, La «ordinatio» del «Rams de Flores» de Juan Fernández de Heredia, in: Fortuño Llorens, Santiago/Martínez Romero, Tomás (edd.), Actes del VII Congrés de l'Associació Hispànica de Literatura Medieval, vol. 1, Castelló de la Plana, Publicacions de la Universitat Jaume I, 1999, 397-409.

Camus Bergareche, Bruno, Cuantificadores I. Los cuantificadores propios, in: Company Company (2009a), vol. 2, 883-960.

Company Company, Concepción, Frecuencia de uso y contacto lingüístico. La construcción artículo indefinido + posesivo + sustantivo en el español americano, Spanish in Context 2:2 (2005) 131-156. 
Company Company, Concepción (ed.), Sintaxis histórica de la lengua española. Segunda parte:

la frase nominal, 2 vol., México, FCE/UNAM, 2009 (=2009a).

Company Company, Concepción, Artículo +posesivo +sustantivo y estructuras afines, in: Company Company (2009a), vol. 1, 761-880, 2009 (= 2009b).

Cornu, Jules, Melanges espagnols, Romania 13 (1884), 285-314.

Eberenz, Rolf, El español en el otoño de la Edad Media, Madrid, Gredos, 2000.

Enguita, José María, Sobre el aragonés medieval, in: Elvira, Javier, et al. (edd.), Lenguas, reinos y dialectos en la Edad Media ibérica. La construcción de la identidad. Homenaje a Juan Ramón Lodares, Madrid/Frankfurt am Main, Iberoamericana/Vervuert, 2008, 83-105.

Enguita, José María, Variedades internas del aragonés medieval, in: Lagüéns, Vicente (ed.): Baxar para subir. Colectánea de estudios en memoria de Tomás Buesa Oliver, Zaragoza, Institución «Fernando el Católico», 2009, 111-150.

Enguita, José María/Lagüéns, Vicente, El dialecto aragonés a través de algunos documentos notariales del siglo XIII. Una posible interpretación de variantes, in: Homenaje al Profesor Emérito Antonio Ubieto Arteta, Zaragoza, Facultad de Filosofía y Letras, 1989, 383-398.

García Martín, José María, La expresión de la posesión y fenómenos conexos del latín al español y a las demás lenguas románicas. Semejanzas y diferencias, in: Castillo Lluch, Mónica/ López Izquierdo, Marta (edd.), Modelos latinos en la Castilla medieval, Madrid/Frankfurt, Iberoamericana/Vervuert, 159-184, 2010.

Geijerstam, Regina af, Sobre Heredia i el bilingüisme medieval aragonès-català, in: Bruguera, Jordi/Massot i Muntaner, Josep (edd.), Actes del Cinqué Col-loqui Internacional de Llengua i Literatura Catalanes, Barcelona, Publicacions de l'Abadia de Montserrat, 1980, 495-510.

Geijerstam, Regina af, «La Grant Crónica de Espanya»: Problemas de su edición y estudio, in: Egido, Aurora/Enguita, José María (edd.), Juan Fernández de Heredia y su época. IV Curso sobre la lengua y literatura en Aragón, Zaragoza, Institución «Fernando el Católico», 1996, 155-169.

Haensch, Günther, Las hablas de la Alta Ribagorza, Zaragoza, Institución «Fernando el Católico», 1960.

Herraiz Pareja, Marcos J./Álvarez Rodríguez, Adelino, cf. Eut. (en 5.1 Fuentes).

Keniston, Hayward, The Syntax of Castilian Prose. The Sixteenth Century, Chicago, University of Chicago Press, 1937.

Lapesa, Rafael, Sobre el artículo con posesivo en castellano antiguo, in: Coseriu, Eugenio/ Stempel Wolf-Dieter (edd.), Sprache und Geschichte. Festschrift für Harri Meier, München, Fink, 1971, 277-296 (recogido in: Estudios de morfosintaxis del español, vol. 1, Madrid, Gredos, 1971, 416-435).

Lausberg, Heinrich, Lingüística románica, vol. 2: Morfología, Madrid, Gredos, 1965.

Menéndez Pidal, Ramón, El dialecto leonés, Revista de Archivos, Bibliotecas y Museos 14 (1906), 128-172 y 294-311.

Menéndez Pidal, Ramón, Cantar de mio Cid: texto, gramática y vocabulario, Madrid, 1908-1911.

Pato, Enrique, La estructura posesiva «una mi amiga» en el español de Guatemala, in: Palacios, Azucena/García Tesoro, Ana Isabel (edd.), El indigenismo americano III, Valencia, Universitat de València, 2002, 121-154.

Pino Serrano, Laura, Sobre a construcción artigo +posesivo +nome nas linguas románicas (achega para un estudio comparativo), in: Lorenzo Vázquez, Ramón/Álvarez Blanco, Rosario (edd.), Homenaxe à profesora Pilar Vázquez Cuesta, Santiago, Universidade de Santiago de Compostela, 1996, 213-226. 
Rohlfs, Gerhard, Grammatica storica della lingua italiana e dei suoi dialetti, 3 vol., Torino, Einaudi, 1966-1969.

Romero Cambrón, Ángeles, Sobre el origen de los posesivos «tuyo» $y$ «suyo», Cahiers d’Études Hispaniques Médiévales 32 (2009), 83-100.

Vives, José, Juan Fernández de Heredia, Gran Maestre de Rodas. Vida, obra y formas dialectales, Barcelona, Balmes, 1927. 